\title{
FEMTOSECOND LASER MICROMACHINING OF SINGLE-CRYSTAL SUPERALLOYS
}

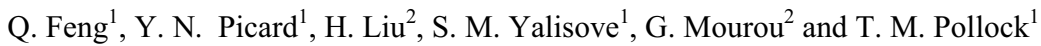 \\ ${ }^{1}$ University of Michigan, Department of Materials Science and Engineering, Ann Arbor, MI 48109 \\ ${ }^{2}$ University of Michigan, Center for Ultrafast Optical Science, Ann Arbor, MI 48109
}

Keywords: Femtosecond laser, Laser drilling, Superalloy, Single crystal, Thermal barrier coatings (TBC)

\begin{abstract}
Investigations on femtosecond laser micromachining of single crystal superalloys with and without plasma-sprayed thermal barrier coatings were conducted under laser fluences ranging from $0.1 \mathrm{~J} / \mathrm{cm}^{2}$ up to $160 \mathrm{~J} / \mathrm{cm}^{2}$. Micromachining was carried out in air using a titanium:sapphire laser system $(\lambda=780 \mathrm{~nm})$ operating at a repetition rate of $1 \mathrm{kHz}$ and delivering individual pulses of $\sim 150$ fs duration. The ablation threshold of the single crystal superalloy was determined as $203 \pm 20 \mathrm{~mJ} / \mathrm{cm}^{2}$. Laser-induced damage was examined by means of scanning electron microscopy and transmission electron microscopy. These studies indicate a complete absence of any melting, recast layers, heat-affected zones or microcracks in the vicinity of the machining area. The only form of damage observed in the single crystal superalloy machined near or above the ablation threshold was a laser-induced plastically deformed layer with a maximum extent of $\sim 5 \mu \mathrm{m}$. Machining through ceramic thermal barrier coatings on a superalloy produced no delamination along the superalloy/coating interfaces or cracks within the TBC or bond coat. The residual roughness of the machined surface was in the sub-micron range. The present study suggests that femtosecond laser micromachining is a very promising technique for production of finescale features in multi-layer material systems for aerospace and power generation components.
\end{abstract}

\section{Introduction}

Multiple generations of single crystal superalloys and coatings have substantially contributed to the continuous improvement in the temperature capability of aircraft and power generation turbine engines. Metal surface temperatures of hot-section components in advanced turbine-engines have approached $\sim 1150^{\circ} \mathrm{C}$ [1] with the use of single crystals and thermal barrier coatings (TBCs) in conjunction with cooling technologies. These advances in performance have required the development of sophisticated processing approaches, including Bridgman growth of single crystals [2], plasma spraying or electron beam physical vapor deposition (EBPVD) of bond coats and ziconia-based TBCs [3] and an array of machining processes.

Complex cooling schemes are designed into hot-section components such as turbine blades, combustion liners and nozzle guide vanes. Cooling holes control heat transfer and promote the passage of the coolant over the surfaces of these components. Modern aircraft engines contain up to 100,000 such cooling holes [4], which apparently are processed with a significant production time and labor cost. Challenges in conventional machining include mechanical tool wear and difficulty with drilling at high angles of incidence for hard ceramics and superalloys. The application of electrical discharge machining (EDM) technology is limited to conductive materials, and ceramic-based TBC-coated components can not be machined in this manner. Other processing techniques, such as electrochemical machining (ECM), electron beam machining or microcutting are challengeing for ceramics and alloys and suffer from high cost of tools and consumables and long production time. In the last two decades, laser machining has become competitive with some of the above-mentioned techniques. Conventional nanosecond lasers have been accepted as an economical processing approach for drilling thousands of closely spaced holes in aero-engine components with high production rates and reproducibility [5]. For example, at Singapore in 1990 , about $12 \%$ of all industrial lasers were used for drilling holes for components in the aerospace industry [6].

Laser machining is a contact-free processing technique which utilizes a focused laser beam with high power intensity to remove material by either vaporization and/or melt ejection [5]. It is particularly suitable for machining hard and brittle materials, and thus has been applied to drill cooling holes in TBC-coated superalloys, including both the ceramic layer and metallic layers. However, laser-drilled holes in aero-engine components must comply with strict quality standards for in-service use. Conventional nanosecond $\left(10^{-9} \mathrm{~s}\right)$ and picosecond $\left(10^{-12} \mathrm{~s}\right)$ laser systems produce distinct heat-affected zones and recast layers, since there is enough time for a thermal pulse to propagate into the material $[7,8,9]$. Therefore, a number of processing defects are encounted including spatter, remelted layers, microcracking, tapering of the drilled hole as well as the delamination of interfaces in the case of TBCs $[4,5,10,11,12]$. Laser-induced cracking in TBC-coated superalloys has been observed at both the bond coat/substrate and bond coat/TBC (top coat) interfaces [13, 14]. Previous parametric studies revealed that the quality of drilled holes depends on material properties and the optimization of laser processing parameters, such as laser fluence, pulse duration, pulse repetition rate and pulse shape $[4,12,15]$. However, the above-mentioned processing defects are inherent to these laser machining processes. They can not be completely eliminated and therefore potentially reduce the component life. The removal of these defects through additional finishing processes results in additional production time and labor cost.

The development of the chirped pulse amplification (CPA) technique in the mid-1980s [16] has recently led to commercial availability of powerful and reliable femtosecond $\left(10^{-15} \mathrm{~s}\right)$ laser systems. They open new possibilities for high quality material machining. Due to the ultrashort pulse duration ( 100 fs), which is less than the heat diffusion time $(\sim 10 \mathrm{ps})$, the material removal 
Table 1. Nominal compositions of single crystal superalloys MK-4 [19] and René N5 (wt.\%)

\begin{tabular}{|c|c|c|c|c|c|c|c|c|c|c|}
\hline Alloy & $\mathrm{Al}$ & $\mathrm{Co}$ & $\mathrm{Cr}$ & $\mathrm{Mo}$ & $\mathrm{Re}$ & $\mathrm{Ta}$ & $\mathrm{Ti}$ & $\mathrm{W}$ & Minor elements & $\mathrm{Ni}$ \\
\hline MK-4 & 5.7 & 9.5 & 6.3 & 0.6 & 3.0 & 6.7 & 0.8 & 6.6 & $0.3 \mathrm{Hf}, 0.03 \mathrm{C}, 0.006 \mathrm{~B}, 0.003 \mathrm{Mg}$ & $\mathrm{Bal}$. \\
\hline René N5 & 6.2 & 7.5 & 7.0 & 1.5 & 3.0 & 6.5 & -- & 5.0 & $0.15 \mathrm{Hf}, 0.05 \mathrm{C}, 0.004 \mathrm{~B}, 0.01 \mathrm{Y}$ & Bal. \\
\hline
\end{tabular}

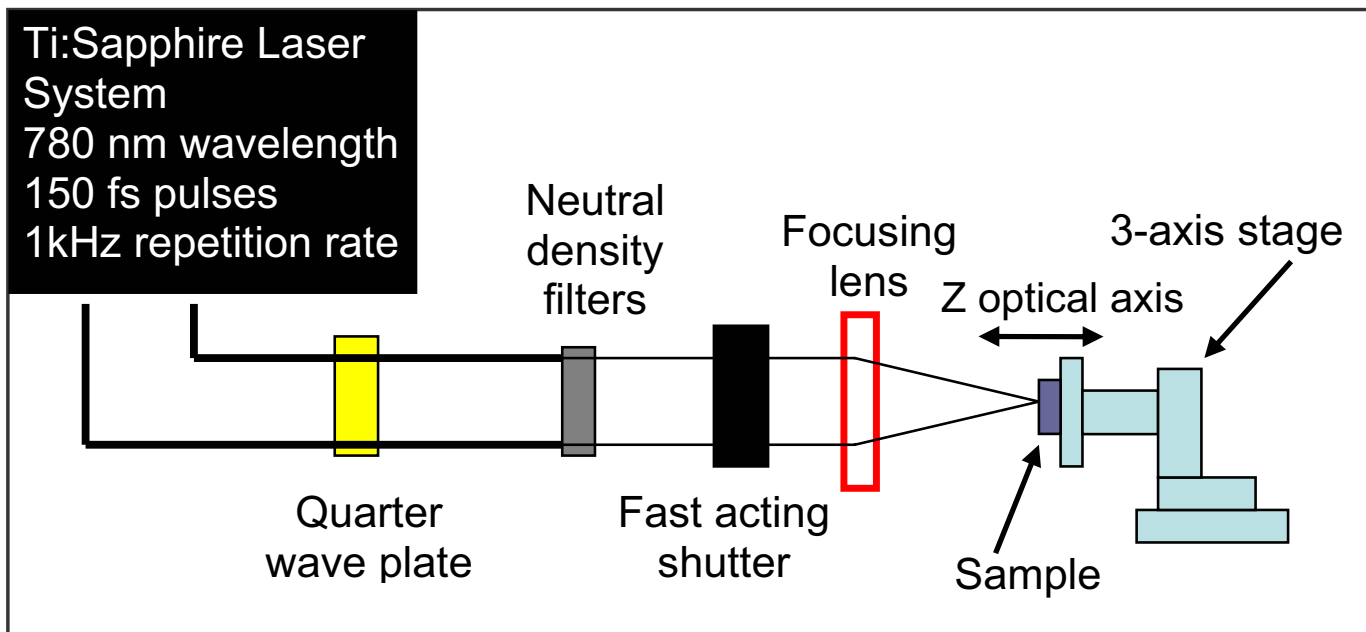

Figure 1. A sketch of the experimental setup for laser micromachining

process is a direct solid-vapor (or solid-plasma) transition with a negligible heat-affected zone. Thus, any collateral damage to the surrounding machined area is minimized [7]. Consequently, the process efficiency is much higher compared to conventional laser systems due to minimized energy loss into the bulk material and the ablation threshold is reduced [7, 8, 17]. Additionally, femtosecond lasers have the potential to serve as a straightforward processing technique that does not require any additional postprocessing or special gas environment. These lasers allow extremely precise processing of nearly all kinds of solid materials including polymers, semiconductors, glasses, metals, ceramics and composite materials with excellent reproducibility [18]. However, to date, there have been very limited studies on laser drilling of Ni-base single crystal superalloys by femtosecond laser systems.

The objective of the present study is to investigate femtosecond laser micromachining on single-crystal superalloys with and without TBCs. Laser-induced microstructural change and material damage were characterized in detail via scanning electron microscopy (SEM) and transmission electron microscopy (TEM). The results of these studies are compared with previous studies on nanosecond laser machining. The thermal and mechanical effects associated with this laser machining process and the specific advantages of femtosecond laser machining of aero-components are discussed.

\section{Experimental}

Two types of materials were used for femtosecond laser micromachining studies: bulk single crystal superalloy and TBC-coated superalloy. The bulk alloy is a second generation single crystal superalloy, MK-4, provided by Alstom Power Ltd., Switzerland. The as-solidified single crystal alloy MK-4 was heat-treated including solution and aging treatments. Coupon samples were prepared by the conventional metallographic procedures and finally polished with $0.05 \mu \mathrm{m}$ suspended alumina powder. Selected samples were lightly-etched in a solution of $1 \% \mathrm{HF}, 33 \%$ $\mathrm{CH}_{3} \mathrm{COOH}, 33 \% \quad \mathrm{HNO}_{3}$ and $33 \% \quad \mathrm{H}_{2} \mathrm{O}$ before the laser micromachining. The TBC-coated superalloy was sectioned from a turbine airfoil provided by GE Power Systems. The plasmasprayed TBC system consisted of a yttria stabilized zirconia (YSZ) ceramic layer bonded to a René N5 substrate superalloy by means of a CoNiCrAlY bond coat. The nominal compositions of both superalloys MK-4 [19] and René N5 are listed in Table 1.

Figure 1 illustrates the experimental setup for the laser micromachining. The micromachining experiments were carried out in air using a commercially available Ti:sapphire laser system, emitting a wavelength of $780 \mathrm{~nm}$ with a repetition rate of $1 \mathrm{kHz}$ and a pulse duration of $150 \mathrm{fs}$. The specimens were mounted on a three-axis manual or computer-driven motorized stage. The output beam of the laser system was linearly polarized and further to be circularly polarized via means of a quarter wave plate. The laser beam was focused using a plano-convex or aspheric lens with a focal length of $350 \mathrm{~mm}$ or $18.4 \mathrm{~mm}$ (selected based on experimental objectives), and directed to a focal point on the specimen surface. The laser energy was varied in the range of $8 \mathrm{~nJ}$ to $775 \mu \mathrm{J}$ per pulse using neutral density filters, which were placed in the laser beam path prior to the focal lens. The number of laser pulse exposures was controlled using a fast acting shutter.

The microstructural characteristics of areas around the lasermachined regions were investigated using an optical microscope and a Philips/FEI XL30FEG scanning electron microscope (SEM) operated in secondary electron (SE) and back-scattered electron (BSE) imaging modes. The laser-induced deformation substructures were studied via transmission electron microscopy (TEM). TEM specimens were sectioned normal to the $<001>$ solidification direction from the heat-treated alloy MK-4 and 


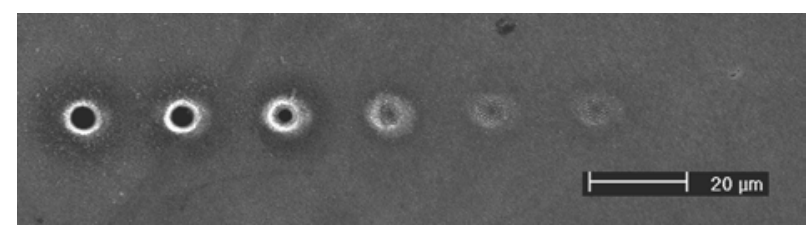

Figure 2. Typical SEM microstructure of an array of laser-machined holes in single crystal superalloy MK-4 using a series of multiple laser shots operating at a fluence of $3.13 \mathrm{~J} / \mathrm{cm}^{2}$.

mechanically thinned to $\sim 100 \mu \mathrm{m}$ in thickness, followed by twinjet electro-polishing in a solution of $10 \%$ perchloric acid, $9 \%$ distilled water, $13 \%$ butyl cellusolve and $68 \%$ methanol at $-40^{\circ} \mathrm{C}$ and $20 \mathrm{~V}$. For detailed studies on damage development, thinned TEM foils were then mounted in a three-axis computer-driven stage and machined by the femtosecond laser over a $2 \mathrm{~mm} \times 2$ $\mathrm{mm}$ area using different laser fluences, producing a grid of lasermachined holes with a spacing of $\sim 25 \mu \mathrm{m}$. Each hole was drilled by scanning the sample through the focal point of the laser beam at a speed of $2 \mathrm{~mm} / \mathrm{s}$, resulting in 50-200 pulses incident on the surface at a fluence above the ablation threshold. The focused spot size of the laser beam was 3-5 $\mu \mathrm{m}$ in diameter on the foil surface. The TEM investigations were conducted using a JEOL 2010F or a Philips CM12 transmission electron microscope at an accelerating voltage of $200 \mathrm{kV}$ or $120 \mathrm{kV}$, respectively.

\section{Results}

\section{Laser micromachining of bulk single crystal superalloy}

The laser ablation experiments were conducted first on the bulk single crystal alloy MK-4. Figure 2 is a SEM image showing an array of micro-holes machined by the femtosecond laser operating at a $150 \mathrm{fs}$ pulse duration and a fixed fluence $3.13 \mathrm{~J} / \mathrm{cm}^{2}$ with a decreasing number of pulses per hole $(2000,500,100,20,5,2)$ from the left side. Further, a series of arrays of laser-machined holes were generated at different laser fluences. The ablation threshold of this material was determined as $203 \pm 20 \mathrm{~mJ} / \mathrm{cm}^{2}$ based on the size of the ablated regions, the focused laser beam size and the Gaussian beam profile.

Figure 3(a) shows the typical $\gamma+\gamma^{\prime}$ microstructure in the lightlyetched sample of alloy MK-4, where a spot of approximately 4 $\mu \mathrm{m}$ in diameter was generated by 2 laser pulses at a fluence of 785 $\mathrm{mJ} / \mathrm{cm}^{2}$, close to 4 times the ablation threshold. No traces of melted material are apparent. However, nano-scale particles (bright contrast) re-deposited inside and around the spot from the plasma created by the laser radiation. Additionally, a fine scale ripple pattern can be observed at the surface of the spot. Figure 3(b) shows a machined region after 2000 laser pulse shots at the same fluence in the same sample. More plasma debris appears and partially shields the $\gamma+\gamma$ ' microstructure. There are still no indications of damage in the form of a recast layer (re-solidified material accumulated on the side wall of the hole), microcracking or spatter (re-solidified material on the hole surface) in the vicinity of the hole. These features were confirmed by TEM investigations, described in the next section. After initial investigation, the same sample was subjected to ultrasonic cleaning in methanol for 5 minutes. Figures 3(c) and (d) show the same regions as Figures 3(a) and (b), respectively, after ultrasonic cleaning. The nano-scale particles were not strongly bonded to the substrate and were significantly reduced in density or were completely removed during ultrasonic cleaning. This suggests that the particles are plasma debris and not melted particles impacting the sample surface. However, it was noted that the diameter of the hole at the top was larger than at the bottom, with a taper similar to that observed with conventional laser machining [5].

Figures 3(e) and (f) show a spot and a hole machined at 2 and 2000 laser shots, respectively, at a fluence of $3.13 \mathrm{~J} / \mathrm{cm}^{2}$, which is about 16 times the ablation threshold. The general characteristics are similar to those generated at the low fluence shown in Figures 3(a)-(d), although more plasma debris appears around the holes. The size of the spot/hole caused by the high laser fluence is generally larger. The residual roughness of the hole surface on the laser-machined region is in the sub-micron range.

\section{$\underline{\text { TEM observations }}$}

Laser-induced damage at the scale of individual microstructural features was evaluated by machining pre-fabricated TEM foils. With this approach, no additional processing of the material is necessary after laser micromachining and direct TEM imaging of the as-machined material is possible.

Figure 4(a) is a bright field TEM image close to the $<001>$ zone axis, presenting the typical microstructure of the heat-treated single crystal alloy MK-4 prior to laser micromachining. It consists of cuboidal $\gamma^{\prime}$ precipitates and a $\gamma$ matrix with occasional dislocations, marked by arrows. Such pre-jet-polished TEM foils were micro-machined with the femtosecond laser using a $150 \mathrm{fs}$ pulse. One of machined foils is shown in Figure 4(b) as a TEM bright-field image taken at a very low magnification. The large hole at the center of the thin foil was a consequence of the standard jet-polishing foil preparation procedure performed before the machining. The jet-polished hole is surrounded by an array of multiple fine holes, which were each laser-machined with 200 pulses. The size of laser-machined holes generally decreased with the foil thickness with the maximum size being $\sim 5 \mu \mathrm{m}$ in diameter.

Figure 5 is a bright-field TEM image showing the typical microstructure near the edge of one laser-machined hole at the right side, which is close to the edge of the TEM jet-polished hole to the left. The laser-machined hole was produced with the laser fluence of $2.33 \mathrm{~J} / \mathrm{cm}^{2}$, over ten times higher than the ablation threshold of alloy MK-4. Laser-induced plastic deformation was clearly observed and the area adjacent to the edge of the lasermachined hole can be divided into three regions:

1) a $\sim 2 \mu$ m layer of intensely deformed material;

2) a $\sim 3 \mu \mathrm{m}$ layer with moderate dislocation density;

3 ) a region where there is limited enhancement of dislocations and the structure is nearly dislocation-free.

The dark-contrast nano-scale particles are apparently plasma debris and were observed with decreasing frequency from region 1 to region 3 . It should be noted that some material in region 1 


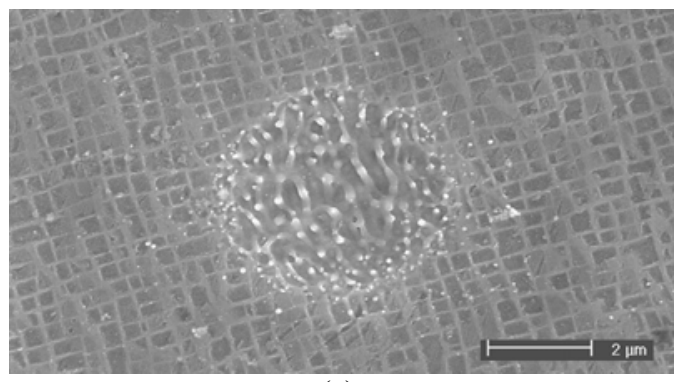

(a)

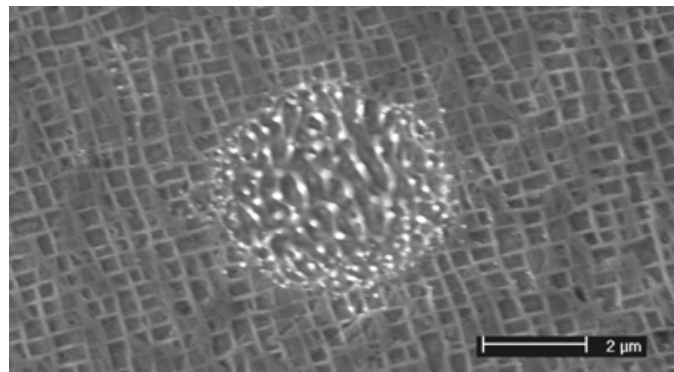

(c)

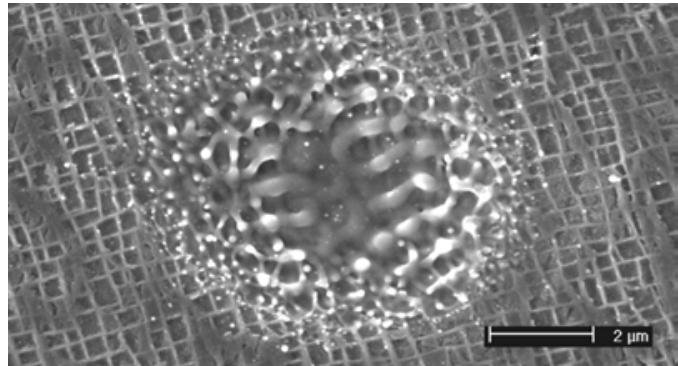

(e)

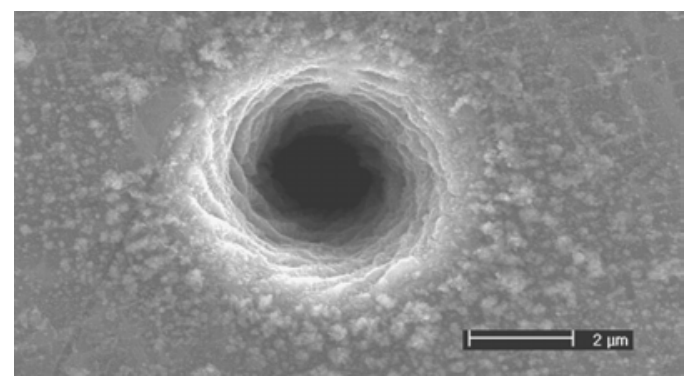

(b)

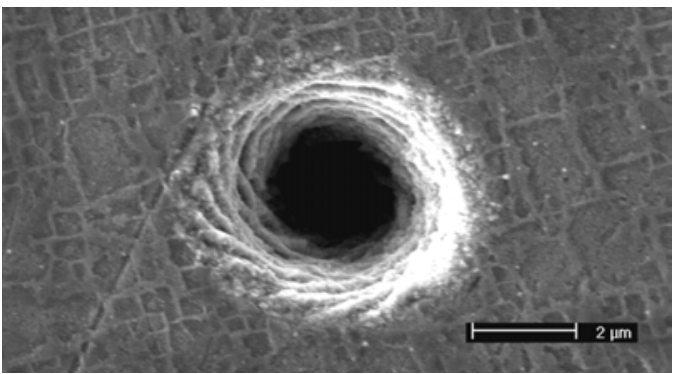

(d)

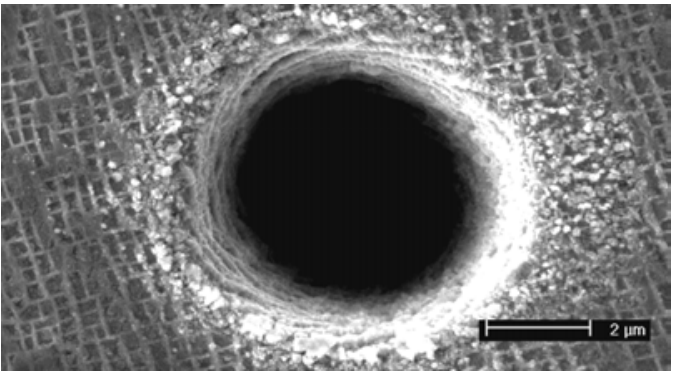

(f)

Figure 3. SEM images of the typical microstructures of laser-machined holes in single crystal alloy MK-4, (a) 2 shots, $785 \mathrm{~mJ} / \mathrm{cm}^{2}$, (b) 2000 shots, $785 \mathrm{~mJ} / \mathrm{cm}^{2}$, (c) 2 shots, $785 \mathrm{~mJ} / \mathrm{cm}^{2}$, (d) 2000 shots, $785 \mathrm{~mJ} / \mathrm{cm}^{2}$, (e) 2 shots, $3.13 \mathrm{~J} / \mathrm{cm}^{2}$, (f) $2000 \mathrm{shots}, 3.13 \mathrm{~J} / \mathrm{cm}^{2}$; (a) and (b) are microstructures before ultrasonic cleaning, (c)-(f) are microstructures after ultrasonic cleaning.

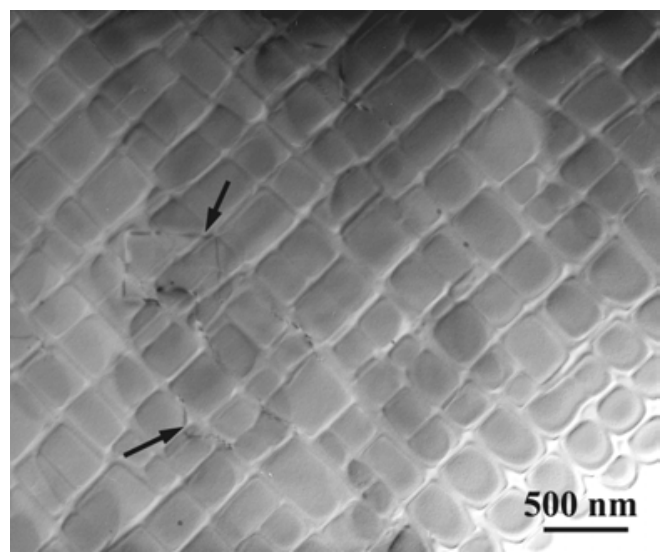

(a)

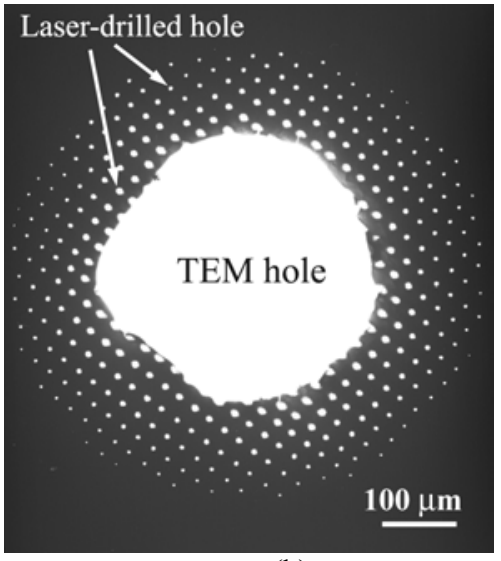

(b)

Figure 4. Bright-field TEM images of heat-treated single crystal alloy MK-4, (a) the typical microstructure before laser machining consists of $\gamma$ and $\gamma^{\prime}$ phases as well as occasional dislocations marked by arrows; (b) a very low magnification image, showing a pre-jet-polished TEM foil was micro-machined by a femtosecond laser, leaving an array of multiple fine holes around the large TEM hole. 


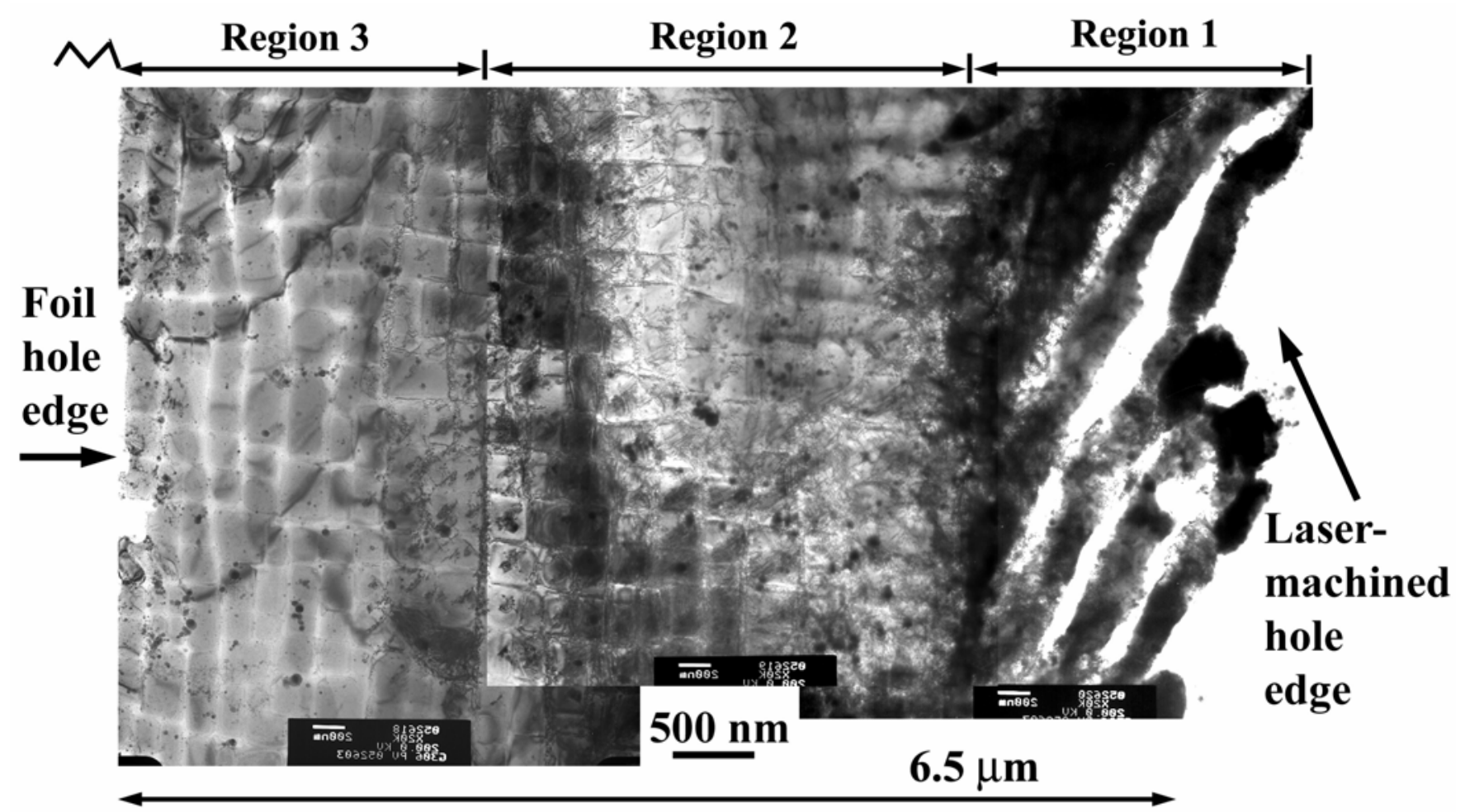

Figure 5. A bright-field TEM image, showing the typical laser-induced deformation microstructure around a laser-machined hole (right side) by a femtosecond laser operating at a fluence of $2.33 \mathrm{~J} / \mathrm{cm}^{2}$ in a pre-jet-polished TEM foil of single crystal alloy MK-4. The microstructure can be divided into three regions according to the deformation behavior. No conventional defects associated with laser machining including microcracks, spatter, heat-affected zone and the recast layer were observed.

appears to have been on the verge of being vaporized during processing and remains with the same striated or rippled appearance. These TEM observations of the rippled structures in the single crystal alloy are consistent with SEM observations (Figure 3 ) and were also observed in the zirconia ceramic coating and a variety of other materials $[8,20,21]$.

Selected area electron diffraction (SAD) analyses were conducted in the area adjacent to the laser-machined hole in order to assess the crystalline nature of the remaining material. Figure 6(a) is a bright-field TEM image of the microstructure in region 1 and the areas for SAD analyses are marked by arrows. Figure 6(b) shows the SAD pattern in the $<001>$ zone axis of the $\left(\gamma+\gamma^{\prime}\right)$ matrix including superlattice diffraction spots of the $\gamma^{\prime}$ phase. It is important to note that it is the same diffraction pattern as observed in regions 2 and 3. There were, however, a few degrees of deviation due to the foil bending. The SAD pattern taken at the hole edge is shown in Figure 6(c) and again presents the $<001>$ zone-axis diffraction pattern of the $\gamma$ phase, which also contained the diffuse superlattice spots of the $\gamma^{\prime}$ phase. Electron diffraction analyses clearly indicate that the material remaining in region 1 maintained its monocrystalline character with the same crystal structure and orientation as observed in regions 2 and 3. This suggests that no material transformed from monocrystalline to polycrystalline or even became amorphous material during laser processing. These direct observations also clearly indicate that no melting occurred near the ablated region during femtosecond laser processing. The slightly more diffuse $\gamma^{\prime}$ superlattice diffraction spots shown in Figure 6(c) may occur for several reasons: 1) the material, including the $\left(\gamma+\gamma^{\prime}\right)$ phases, was heavily deformed, 2$)$ the material consisted of a higher volume fraction of the $\gamma$ phase within the first $400 \mathrm{~nm}$ of the machined hole, relative to the base material or 3) some slight preferential vaporization of $\mathrm{Al}$ reduced the volume fraction of precipitates.

In region 2, the dislocation density was significantly less compared to region 1 and isolated dislocations along with dense dislocation networks were observed. This indicates that a strong gradient of plastic deformation was induced by laser machining within a region limited to a few microns around the hole. Figure 7 (a) is a higher magnification image of region 2 in Figure 5, showing the individual dislocations, including segments inside the $\gamma$ matrix channels in multiple-slip configurations and some isolated segments inside the $\gamma^{\prime}$ precipitates. Most dislocations were identified as $1 / 2<011>$ type and they appeared to spread via gliding within the $\gamma$ matrix channels. No stacking faults created by shearing of the $\gamma^{\prime}$ precipitates were observed. Figure $7(\mathrm{~b})$ is a bright field TEM image taken at the region 2 in another lasermachined hole from the same sample. It shows longer dislocation segments with distinct cusped morphologies and shorter bowedout segments between the cusps. This suggests that these dislocations were pinned of the $\gamma-\gamma^{\prime}$ interfaces and underwent glide with the aid of cross-slip within the channels of the $\gamma$ matrix [22]. Again, they were identified as $1 / 2<011>$ type dislocations. 


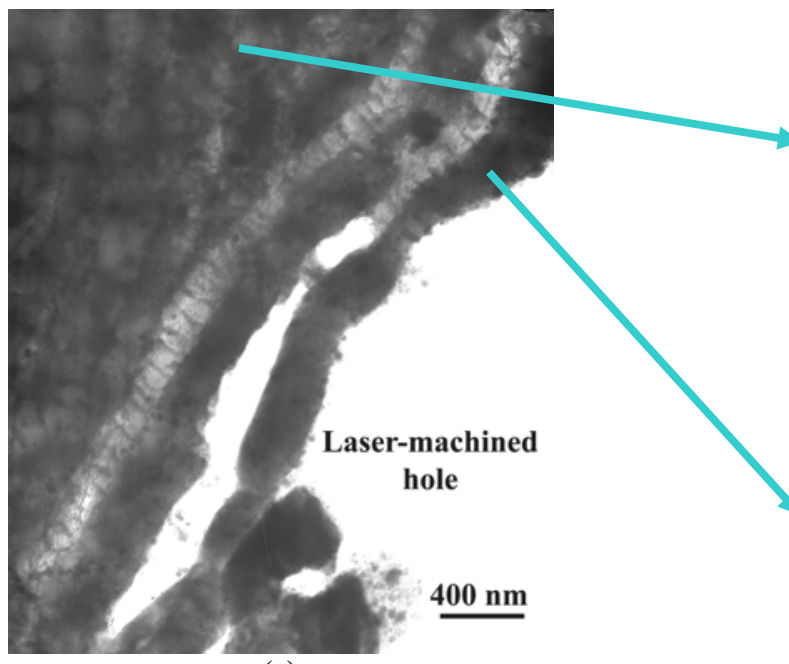

(a)

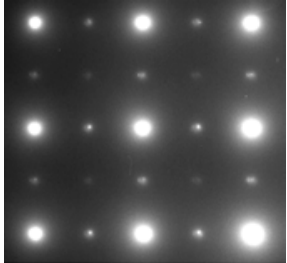

(b)

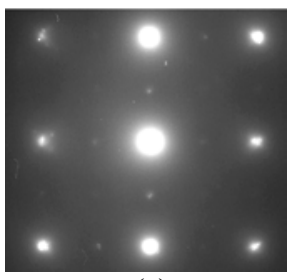

(c)

Figure 6. Single crystal alloy MK-4, (a) a bright-field TEM image of laser-induced deformation microstructure in region 1 of Figure 5, (b) and (c) are SAD patterns in the $<001>$ zone-axis taken from the areas marked in (a), revealing the same crystal structure with the same orientation in both areas, indicating that no melting occurred during laser machining.

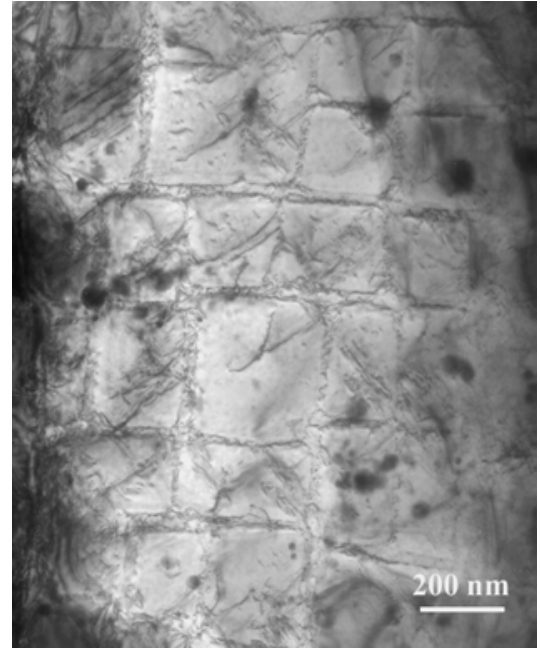

(a)

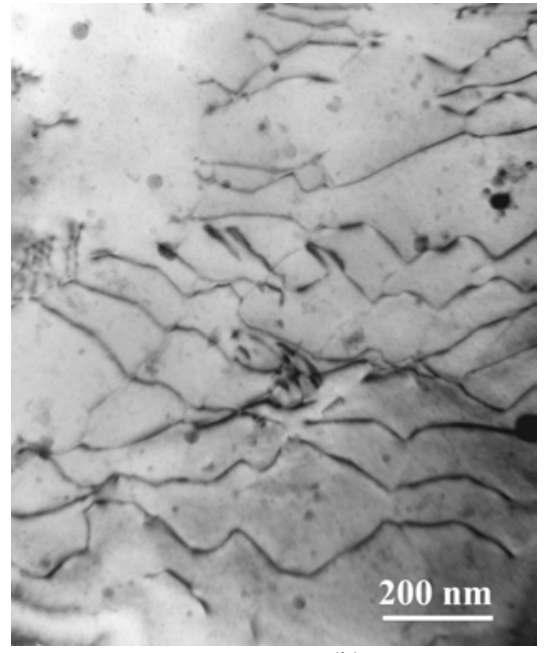

(b)

Figure 7. Bright-field TEM images of laser-induced deformation microstructure in region 2 of Figure 5, (a) showing multiple dislocation slip systems inside the channels of the $\gamma$ matrix with relatively low dislocation density, (b) isolated dislocations demonstrating the distinct cusped morphology.

Figure 8 (a) is a bright field TEM image of the heat-treated alloy MK-4, showing a hole drilled by a femtosecond laser operating at the fluence of $196 \mathrm{~mJ} / \mathrm{cm}^{2}$, which is in the range of the ablation threshold of the material $\left(203 \pm 20 \mathrm{~mJ} / \mathrm{cm}^{2}\right)$. It clearly demonstrates no melting, an absence of microcracking and no heat-affected zone or spatter around the hole. The size of the hole is about $4.3 \mu \mathrm{m}$ in diameter, very close to the focused laser spot size. The general characteristics of the microstructure adjacent to the laser-machined hole are similar to the one drilled at a high fluence (Figure 5), except the deformation region and the dislocation density was significantly reduced, indicating very limited laser-induced deformation at the ablation threshold. Figure $8(\mathrm{~b})$ is a high magnification image of area $\mathrm{A}$ in Figure 8(a) within
$2 \mu \mathrm{m}$ of the edge of the laser-drilled hole. It shows a significant density of isolated dislocations and dislocation networks, again suggesting that the laser machining resulted in activation of multiple slip systems. Most of laser-induced dislocations in this sample were again characterized as $1 / 2<011>$ type and appeared to glide inside through the $\gamma$ matrix channels.

To summarize, TEM microstructural investigations of material subjected to femtosecond laser machining at fluences ranging from 1 to $\sim 11$ times the ablation threshold clearly demonstrate the absence of defects typically encountered with conventional processes, including melted zones, heat-affect zones or 


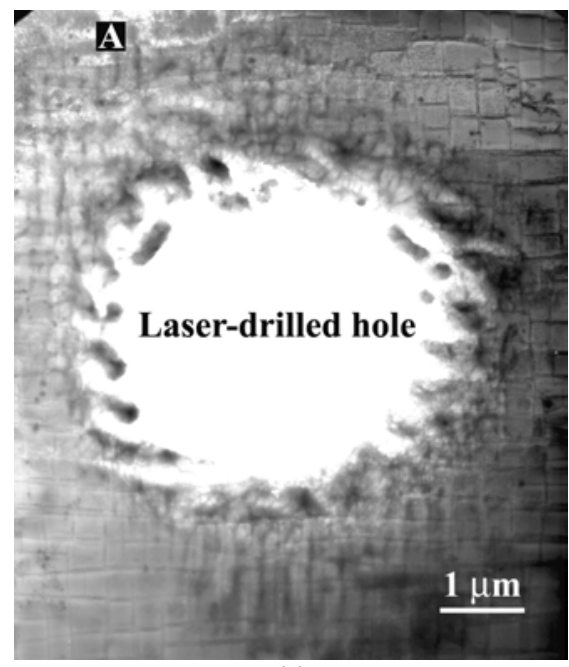

(a)

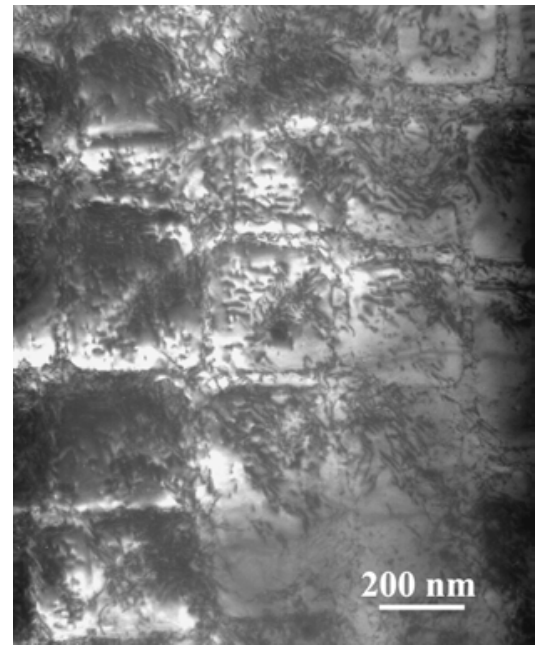

(b)

Figure 8. Bright-field TEM images of single crystal alloy MK-4, (a) a hole was drilled by a femtosecond laser operating at a fluence of 196 $\mathrm{mJ} / \mathrm{cm}^{2}$ in a pre-jet-polished TEM foil, the region adjacent to the hole showing a complete absence of melting, microcracking and a lower dislocation density, (b) a large magnification image of area A in (a), showing a significant dislocation density and multiple types of dislocations inside the channels of the $\gamma$ matrix and at the $\gamma-\gamma$ ' interfaces.

microcracks. Material removal was accompanied by a direct ablation (vaporization) process. Laser-induced plastic deformation did occur within a layer less than $5 \mu \mathrm{m}$ in extent around the edge of the hole. The extent of the plastically-deformed damage increased as the fluence increased beyond the ablation threshold.

\section{$\underline{\text { Laser micromachining of the TBC-coated superalloy }}$}

Two different types of femtosecond laser micromachining experiments were conducted in a TBC-coated superalloy René N5: (1) machining of the top coat (ceramic layer), (2) machining from the surface of the TBC through the bond coat/superalloy interface.

Figure 9(a) is a SEM image of the plan-view of a YSZ ceramic layer (top coat) in the TBC-coated superalloy, showing four trenches in the ceramic layer machined by a femtosecond laser operating at the fluence of $160 \mathrm{~J} / \mathrm{cm}^{2}$. From the top view, no cracks, spatter or plasma debris were observed around the trenches. The cross-sectional view of the same TBC-coated sample through the laser-machined trenches is shown in Figure 9(b). Again there was no obvious laser-induced microcracking or recast layers around these trenches in the ceramic layer. Figure 9(c) is a SEM image at a higher magnification, presenting the typical microstructure of the trench surface after the femtosecond laser micromachining. It shows the laser-induced sub-micron roughness that is typical of femtosecond machined surfaces in a wide range of materials including metals and glass $[8,21]$.

Figure $9(\mathrm{~d})$ is a backscattered-electron (BSE) SEM image, showing the cross-sectional view of a trench, machined by a femtosecond laser operating at the fluence of $18 \mathrm{~J} / \mathrm{cm}^{2}$. The trench was drilled through the top coat/bond coat and bond coat/superalloy interfaces. It should be noted that the machining process did not produce any delimination of the top coat/bond coat or bond coat/superalloy interfaces, even the trench passed through a defect at the bond coat/superalloy interface (marked by an arrow) during laser machining. These interfaces are well known as sites for laser-induced damage via conventional processes, due to high mismatch in thermal expansion coefficients of the different layers of materials in TBC-coated superalloys [23].

\section{Discussion}

Advanced aero-engine hot-section components have evolved to complex, multi-layer material systems containing ceramic, intermetallic and metallic layers, each with significantly different material properties. The material complexity presents a challenge for optimization of airfoil cooling designs, due to the difficulty of casting and machining these features into the airfoil. Laser drilling is among the techniques that are useful for drilling cooling passage features. However, a number of defects are inherently associated with current laser drilling systems. As mentioned previously, these include spatter, recast layer, microcracks and taper of the drilled hole, as well as delamination at the interfaces of dissimilar material layers [4, 5, 10, 11, 12, 13, 14]. These defects affect the metallurgical and geometrical quality and presumably limit the performance of materials. Therefore, advanced laser techniques that minimize damage during machining are desirable.

The physics of laser-material interaction is complex, and depends on laser power, the time of interaction and material properties. Laser-induced material removal involves the following steps: absorption of the laser energy by the material, redistribution of the absorbed energy within the target material, and the ablation of material by evaporation and/or melt ejection [7, 9, 24]. When a laser beam is deposited into the material surface, the free electrons are heated to a very high temperature by absorbing the laser energy. The energy is subsequently transferred to the ions or the lattice and elevates its temperature through electron-lattice coupling. The thermalization time for this coupling to occur is in the range of 1.5-3 ps, increasing with the laser fluence [9]. If the 


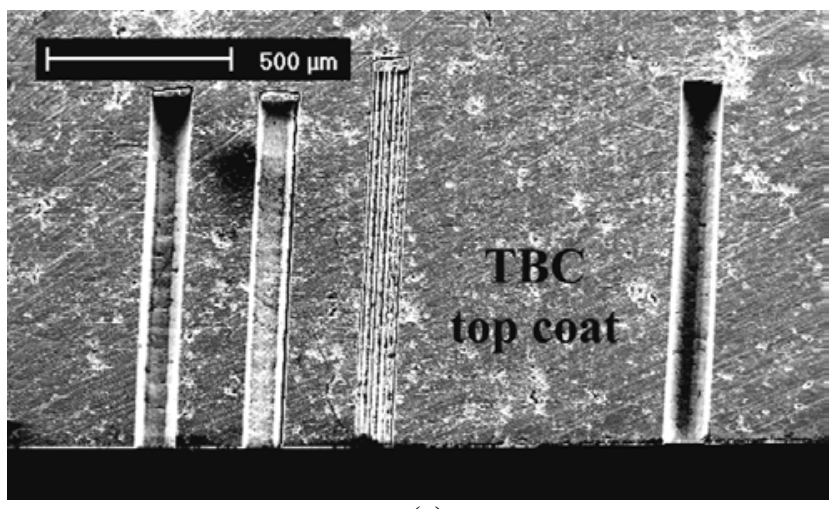

(a)

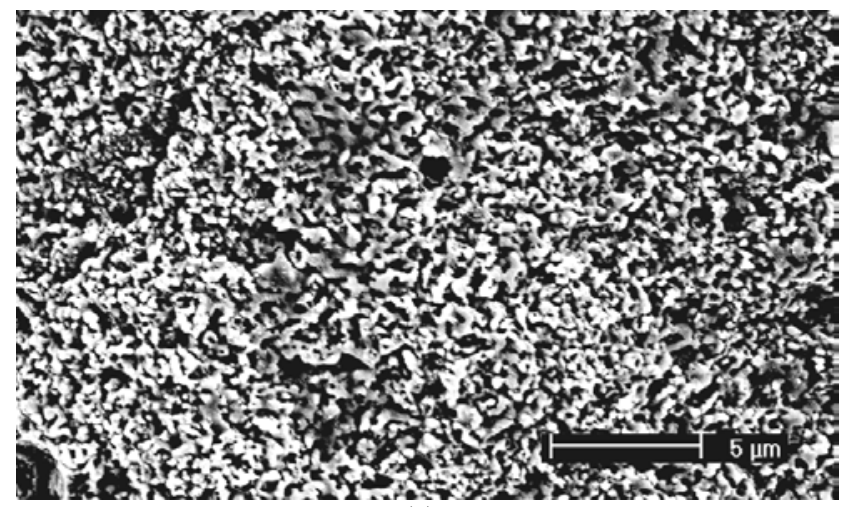

(c)

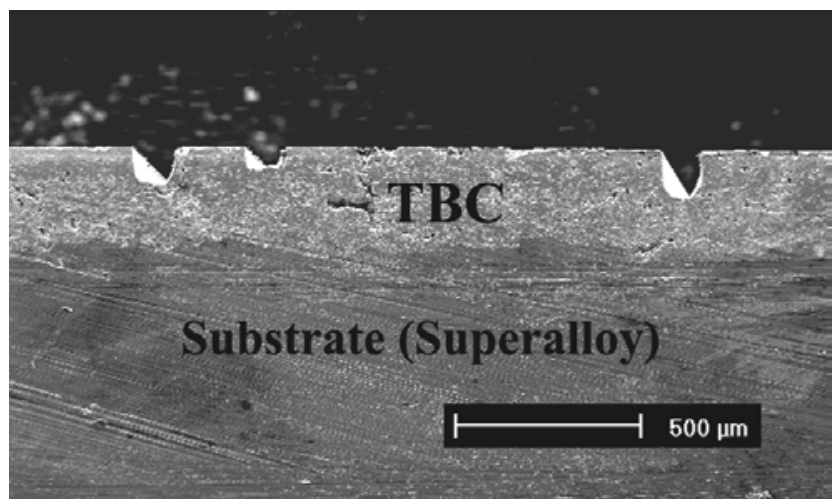

(b)

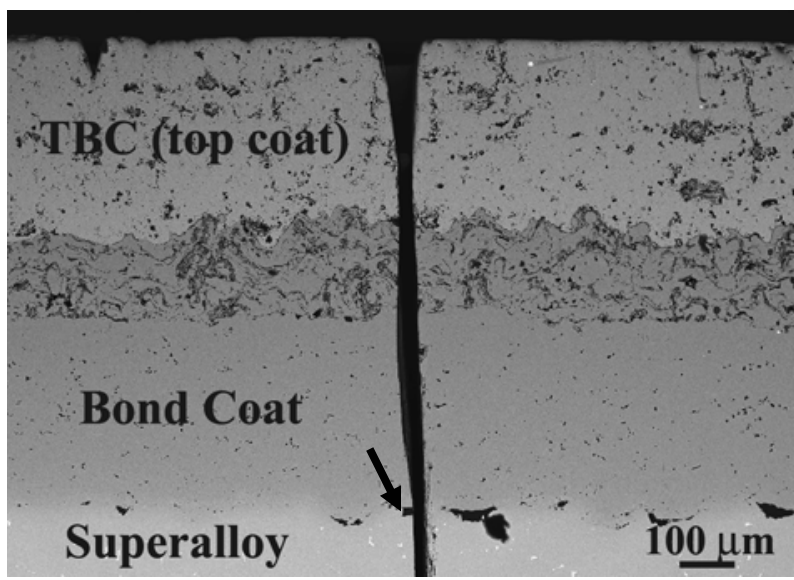

(d)

Figure 9. SEM images of the trenches machined by a femtosecond laser in the TBC-coated superalloy showing no laser-induced processing defects, such as microcracking and recast laser, etc., (a) and (b) are plan view and cross-section view of the trenches machined inside the top coat (ceramic layer), (c) typical microstructure of the trench surface, (d) BSE image, showing the trench machined through top coat/bond coat and bond coat/superalloy interfaces.

laser pulse is longer than the time period for energy transfer from electron to lattice, the volume of material at the laser focus spot is heated by absorption of the laser energy and subsequent energy transfer to the surrounding material. This heat conduction results in the molten and heat-affected zones. This also results in a relatively small volume of material being heated to the point of vaporization. Thus, with the longer laser pulses, the ablation is always accompanied with the formation of larger heat-affected zones and the appearance of a melted layer. For the ultrafast laser pulse with a high power intensity $\left(\sim 10^{13} \mathrm{~J} / \mathrm{cm}^{2}\right.$ in our experiments), the electrons are driven to a very high temperature (far above the vaporization temperature) while the lattice remains unheated during the pulse. If the laser fluence is not far above the ablation threshold, studies in other materials systems have demonstrated that the heat diffusion into the surrounding material is negligible, with the absence of melted material [24]. Therefore, theoretically, high precision machining of aero-engine materials should be possible with femtosecond laser pulses.

One aim of this study was to investigate whether the laser-induced defects during conventional nanosecond laser machining could be avoided by the use of ultrafast laser pulses of high power density. Of particular interest was the development of changes in shape and structure around the laser-machined area. The ablation studies on the bulk single crystal superalloy in the current work indicate that there was no evidence of melting or microcracks after the femtosecond laser machining (Figure 3 and Figure 5). Although there was some nano-scale plasma debris around the hole and on the side wall, this was easily removed by the ultrasonic cleaning leaving a residual roughness of the laser-machined surface of less than $1 \mu \mathrm{m}$. The extent of microstructural degradation was also investigated by TEM on pre-jet-polished TEM foils micromachined by the femtosecond laser for the first time (Figure 5). Electron diffraction analyses using TEM on the area at or close to the edge of the laser-machined hole indicated no loss of single crystal structure or any presence of an amorphous layer (Figure 6). This provides direct proof that no melting occurred and suggests that material removal was completely accomplished by a vaporization process. In the previous studies $[12,25]$, recast layers and heat-affected zones within at least $10 \mu \mathrm{m}$ thickness were observed adjacent to the processed zones in copper, Ni-base superalloys and titanium alloys with nanosecond lasers. The direct ablation that occurs with the use of femtosecond lasers is clearly desirable from the point of view of minimizing damage. It should be noted that the holes exhibited some degree of the taper in the current study, but the optimization of laser processing parameters and more sophisticated machining stages could minimize this problem. Further research on this issue is under progress. 
In general, laser-induced plastic deformation of the materials may result directly from the laser-induced shock wave or indirectly as a consequence of thermally-induced compressive and tensile stresses. These stresses can drive plastic deformation processes in the vicinity of the process zone. Direct experimental assessment of laser-induced deformation must be conducted using TEM techniques. Luft et al. has performed TEM investigations on single crystal silicon machined by a copper vapor laser $(50 \mathrm{~ns}$, $3 \times 10^{8} \mathrm{~J} / \mathrm{cm}^{2}$ ) [25]. Laser-induced damages of the silicon included: 1) the multiple recast layers on the side wall of the hole with the pores between the layers, 2) an $\sim 5 \mu$ m plastically-deformed zone containing multiple-slip dislocations with mainly radial alignment, 3) circumferential cracking between the deformation zone and the defect-free matrix. As mentioned previously, heat diffusion into the adjoining material occurs with such nanosecond pulses. The plastically-deformed region resided within the heataffected zone. The damage zone in the silicon was attributed to tensile stresses that developed in the course of the subsequent cooling process due to local contraction after heat diffusion, resulting in formation of the pores and cracks. For the same laser fluence, the use of the femtosecond laser pulse results in a higher power density $\left(\sim 10^{15} \mathrm{~W} / \mathrm{cm}^{2}\right)$, which is appoximately five orders of magnitude higher than the nanosecond laser $\left(\sim 10^{9}-10^{10}\right.$ $\left.\mathrm{W} / \mathrm{cm}^{2}\right)$. It is known that higher laser power density increases the mechanical load placed on materials due to high ablation and plasma pressures [26, 27]. In the present study of the single crystal superalloy, a layer of plastically deformed material $\sim 5 \mu \mathrm{m}$ in extent was observed. Given that heat diffusion is minimized by the femtosecond pulse, this zone apparently developed in response to the mechanical shock wave.

In general, debonding between the dissimilar ceramic/ intermetallic and intermetallic/metallic interfaces in TBC systems occurs due to residual stresses in the coating systems, which result from the mismatches in thermal expansion coefficients between the multi-layers during processing or in service. Thermal expansion coefficient measurements in TBC-coated superalloys reveal large expansion mismatches [23]. With rapid heating, these mismatches result in the buildup of thermal stress and interface delamination with conventional lasers [4, 10, 13, 14]. During conventional laser machining of these systems, the re-solidified ceramic layer at the side wall of the hole has been observed overlaying the bond boat and substrate, and has been found recently to have the strong effect on the debonding and crack deflecting [14]. However, this did not occur in the present femtosecond study and this is a further evidence for minimization of heat conduction (Figure 9(d)). It also suggests that femtosecond lasers may be particularly useful for machining of layered and/or composite structures containing constituents with widely varying properties.

\section{Summary}

Investigations on the laser machining of single crystal superalloys with and without TBCs with femtosecond pulses reveal the following observations:

1. The ablation threshold for a second generation single crystal superalloy was $203 \pm 20 \mathrm{~mJ} / \mathrm{cm}^{2}$.

2. The residual roughness of the surface on the laser-machined region is less than $1 \mu \mathrm{m}$.
3. There was a complete absence of melting, recast layers, heataffected zones or microcracks around the laser-machined region in a bulk single crystal alloy with a laser fluence in the range of 1-15 times the ablation threshold.

4. The plastic deformation induced by the femtosecond laser machining occurred within a limited region up to $\sim 5 \mu \mathrm{m}$ around the process region.

5. There was no recast layer or delamination of the layers of a TBC/bond coat/superalloy system during femtosecond laser machining from the top surface of the TBC into the base superalloy under the investigated conditions.

The present work suggests that femtosecond laser micromachining is a promising technique for the establishing finescale features in multi-layered turbine airfoil and combustor materials that require high quality, high precision material processing, reproducibility with a high production rate and minimal damage.

\section{Acknowledgements}

Financial support for this research provided by the General Electric Company is gratefully acknowledged.

\section{References}

1. National Materials Advisory Board, Coatings for HighTemperature Structural Materials: Trends and Opportunities, (National Academy Press, Washington, DC, 1996), 8-9.

2. F.L. VerSynder, "Gas Turbine Element", U.S. Patent, $3,260,505,1966$.

3. J.R. Nocholls, "Advances in Coating Design for Highperformance Gas Turbines", MRS Bulletin, 28(9) (2003) 659670 .

4. A. Corcoran, L. Sexton, B. Seaman, P. Ryan, G. Byrne, "The laser drilling of multi-layer aerospace materials systems", J. Mater. Process. Technol. 123 (2002) 100-106.

5. C.Y. Yeo, S.C. Tam, S. Jana, Michael W.S. Lau, "Technical review of the laser drilling of aerospace materials", J. Mater. Process. Technol., 42 (1994) 15-49.

6. S.C. Tam, C.Y.Yeo, Yusoff Md Noor, L.J. Yang, S. Jana, Lennie E.N. Lim, W.S. Lau, "Applications of laser machining in Singapore", Int. Conf. on Productivity '91, Institute of Industrial Engineering of Singapore, 1991, pp. 194-218.

7. B. N. Chichkov, C. Momma, S. Nolte, F. von Alvensleben, A. Tuennermann, "Femtosecond, picosecond and nanosecond laser ablation of solids", Applied Physics A, 63 (1996) 109115 .

8. P. Simon, J. Ihlemann, "Machining of submicron structures on metals and semiconductors by ultrashort UV-laser pulses", Applied Physics A, 63 (1996) 505-508. 
9. K. Dou, E.T. Knobbe, R.L. Parkhill, B. Irwin, L. Matthews, K.H. Church, "Femtosecond study of surface structure and composition and time-resolved spectroscopy in metals", Appl. Phys. A, 76 (2003) 303-307.

10. P. Forget, M. Jeandin, P. Lechervy, D. Varela, "Laser drilling of a superalloy coated with ceramic", Superalloys 1988, ed. G. Maurer, S. Antolovich, C. Lund (Warrendale, PA: The Metallurgical Society, 1988), 553-562.

11. D.K.Y. Low, L, Li, P.J. Byrd, "Spatter prevention during the laser drilling of selected aerospace materials", J. Mater. Process. Technol., 139 (2003) 71-76.

12. S. Bandyopadhyay, J. K. S. Sundar, G. Sundararajan, S. V. Joshi, "Geometrical features and metallurgical characteristics of Nd:YAG laser drilled holes in thick IN718 and Ti-6Al-4V sheets", J. Mater. Process. Technol., 127 (2002) 83-95.

13. J. Kamalu, P. Byrd, A. Pitman, "Variable angle laser drilling of thermal barrier coated nimonic", J. Mater. Process. Tech., 122 (2002) 355-362.

14. K.T. Voisey, T.W. Clyne, "Laser drilling of cooling holes through plasma sprayed thermal barrier coatings", Surface and Coating Technology, 176 (2004) 296-306.

15. B.S. Yilbas, "Parametric study to improve laser hole drilling process", J. Mater. Process. Technol. 70 (1997) 264-273.

16. D. Strickland, G Mourou, "Compression of amplified chirped optical pulses", Opt. Commun. 56 (1985) 219-221.

17. S. Nolte, G. Kamlage, F. Korte, T. Bauer, T. Wagner, A. Ostendorf, C. Fallnich, H. Welling, "Microstructuring with femtosecond lasers", Adv. Eng. Mater., 2 (2000) 23-27.

18. N.H. Rizvi, "Femtosecond laser micromachining: current status and applications", Riken Review, 50 (2003) 107-112.

19. M. Konter, M. Newnham, C. Tönnes, "Monocrystalline Nibase superalloy with $\mathrm{Ti}$, Ta and Hf carbides", U.S. Patent, 5,759,301 (1998).

20. J. Bonse, P. Rudolph, J. Krueger, S. Baudach, W. Kautek, "Femtosecond pulse laser processing of TiN on silicon", Applied Surface Science, 154-155 (2000) 659-663.

21. S. Ameer-Beg, W. Perrie, S. Rathbone, J. Wright, W. Weaver, H. Champoux, "Femtosecond laser microstructuring of materials", Applied Surface Science, 127-129 (1998) 875-880.

22. T.M. Pollock, A.S. Argon, "Creep Resistance of CMSX-3 Nickel-base Superalloy Single-Crystals", Acta Metall. Mater., 40 (1992) 1-30.

23. B. Tryon, T. M. Pollock, M.F.X. Gigliotti, K. Hemker, "Thermal expansion behavior of ruthenium aluminides", Scripta Mater., 50 (2004) 845-848.

24. S. Nolte, C. Momma, H. Jacobs, A. Tunnermann, B.N. Chichkov, B. Wellegehausen, H. Welling, "Ablation of metals by ultrashort laser pulses", J. Opt. Soc. Am. B, 14 (1997) 27162722 .

25. A. Luft, U. Franz, A. Emsermann, J. Kaspar, "A study of thermal and mechanical effects on materials induced by pulsed laser drilling", Appl. Phys. A, 63 (1996) 93-101.

26. J.D. O'Keefe, C.H. Skeen, C.M. York, "Laser-Induced Deformation Modes in Thin Metal Targets", J. Appl. Phys., 44 (1973) 4622-4626

27. D. Devaux, R. Fabbro, L. Tollier, E. Bartnicki, "Generation of shock waves by laser-induced plasma in confined geometry", J. Appl. Phys., 74 (1993) 2268-2273. 